\title{
In vitro bioaccessibility and antioxidant properties of edible bird's nest following simulated human gastro-intestinal digestion
}

\author{
Zhang Yida ${ }^{1,2}$, Mustapha Umar Imam ${ }^{1}$ and Maznah Ismail ${ }^{1,3^{*}}$
}

\begin{abstract}
Background: Edible birds' nest (EBN) is reported to be antioxidant-rich. However, the fate of its antioxidants after oral consumption is not yet reported. To explore this, we hypothesized that EBN antioxidants are released from their matrix when subjected to in vitro simulated gastrointestinal digestion.

Methods: EBN samples were extracted using hot water $\left(100^{\circ} \mathrm{C}\right)$ with or without subsequent sequential enzymatic digestion using pepsin (10,000 units), pancreatin $(36 \mathrm{mg})$ and bile extracts $(112.5 \mathrm{mg})$. Additionally, pH changes (8.9 to 2 and back to 8.9) similar to the gut were applied, and a $10 \mathrm{KDa}$ dialysis tubing was used to simulate gut absorption. The antioxidant capacities of the water extracts of EBN before and after digestion were then determined using ABTS and oxygen radical absorbance capacity (ORAC) assays, while the protective effects of the EBN samples against hydrogen peroxide-induced toxicity in HEPG2 cells were determined using MTT assay and acridine orange $(\mathrm{AO})$ /propidium iodide (PI) staining.
\end{abstract}

Results: Antioxidant assays (ABTS and ORAC) showed that the undigested EBN water extract had little antioxidant activity ( 1 and $1 \%$, respectively at $1000 \mu \mathrm{g} / \mathrm{mL}$ ) while at similar concentrations the digested samples had significantly $(p<0.05)$ enhanced antioxidant activities, for samples inside (38 and 50\%, respectively at $1000 \mu \mathrm{g} / \mathrm{mL}$ ) and outside ( 36 and $50 \%$, respectively at $1000 \mu \mathrm{g} / \mathrm{mL}$ ) the dialysis tubing, representing absorbed and unabsorbed samples, respectively. Cell viability and toxicity assays also suggested that the EBN extracts were non-toxic to HEPG2 cells (cell viabilities of over $80 \%$ at $1000 \mu \mathrm{g} / \mathrm{mL}$ ), while AOPI showed that the extracts protected HEPG2 cells from hydrogen peroxide induced-toxicity.

Conclusions: Based on the findings, it is likely that EBN bioactives are released from their matrix when digested in the gut and then absorbed through the gut by passive-mediated transport to exert their functional effects. However, there is need to confirm these findings using in vivo systems to determine their clinical significance.

Keywords: Antioxidant, Edible bird's nest, Gastro-intestinal digestion

\section{Background}

Edible birds' nest (EBN) has been used traditionally across much of Asia for its health promoting benefits. It is produced by swiftlet species, commonly found in Asian countries like Thailand, Indonesia and Malaysia. Its consumption among Asians has a long history and it is thought to improve overall general health [1,2].

\footnotetext{
* Correspondence: maznahis@upm.edu.my

'Laboratory of Molecular Biomedicine, Institute of Bioscience, Universiti Putra Malaysia, 43400 Serdang, Selangor, Malaysia

${ }^{3}$ Department of Nutrition and Dietetics, Faculty of Medicine and Health Sciences, Universiti Putra Malaysia, 43400 Serdang, Selangor, Malaysia Full list of author information is available at the end of the article
}

Interest in these claims has grown considerably over the years and studies have been conducted to demonstrate the effectiveness of EBN towards the claimed benefits. It is now known that EBN has antioxidant, anti-inflammatory, and bone strengthening properties among others [2-4]. EBN contains many bioactive compounds that are thought to be responsible for its health promoting effects including glucosamine, lactoferrin, sialic acid, amino acids, fatty acids, triacylglycerol, vitamins, minerals and other antioxidants [1,2,5-7].

Antioxidants have received close attention in recent years because of their perceived efficacy towards relieving 
oxidative stress-related diseases, which are thought to be growing in incidence globally. In fact, most chronic diseases have been linked to oxidative stress and studies have demonstrated that the use of antioxidants could play significant roles in reducing risk and in managing the diseases [8]. However, high antioxidant composition does not always equate to better efficacy since nutrikinetic factors could determine the bioavailability of bioactives from food sources and hence their bioactivity [9].

The use of in vitro systems that simulate gastrointestinal digestion has been shown to provide insights into the amounts of bioactives that are likely to be derived from foods when they are consumed. In this regard, foods are subjected to conditions similar to what obtains in the gut and the results indicate whether such conditions would lead to release of antioxidants present in the foods or not [10]. Thus, in this study we demonstrate the effect of simulated gastrointestinal digestion on antioxidant properties of EBN to provide insights on the degree to which antioxidants in EBN are made available after it undergoes digestion.

\section{Methods \\ Reagents}

Hydrogen peroxide $\left(\mathrm{H}_{2} \mathrm{O}_{2}\right)$ was purchased from Bendosen Laboratory Chemicals (Selangor, Malaysia). Pepsin, pancreatin, bile extract, sodium biocarbonate $\left(\mathrm{NaHCO}_{3}\right)$, fluorescein sodium salt, 2,2'-azobis (2-amidinopropane) dihydrochloride (AAPH), dichloro-dihydro-fluorescein diacetate (DCFH-DA), RPMI 1640 medium, fetal bovine serum, antibiotic, potassium persulphate $\left(\mathrm{K}_{2} \mathrm{~S}_{2} \mathrm{O}_{8}\right), 2,2^{\prime}$ azino-bis[3-ethylbenzothiazoline-6-sulphonic acid] (ABTS) reagent, and 3-(4,5-Dimethylthiazol-2-yl)-2,5-diphenyltetrazolium bromide (MTT) powder were purchased from Sigma-Aldrich (St. Louis, MO, USA), while other cell culture materials were purchased from BD Biosciences (NJ, USA).

\section{EBN sample preparation}

EBN was supplied by Blossom View Sdn. Bhd (Terrengganu, Malaysia). Upon collection, it was cleaned under tap water for 5 mins, dried at room temperature and ground into powder manually using mortar and pestle. The ground EBN ( $1 \mathrm{~g}$ ) was dissolved in $100 \mathrm{~mL}$ distilled water, incubated at $37^{\circ} \mathrm{C}$ for $2 \mathrm{~h}$ and boiled $\left(100^{\circ} \mathrm{C}\right)$ for $30 \mathrm{~min}$ afterwards. The rest of the EBN was stored at $-80^{\circ} \mathrm{C}$ until further analysis, while the boiled sample was kept in a shaking incubator (LSI-3016, Daihan Lab tech Co. Ltd, Korea) at $55^{\circ} \mathrm{C}$ and $50 \mathrm{rpm}$ for $3 \mathrm{~h}$. At this point, the $\mathrm{pH}$ (Mettler Toledo, MP 125, Switzerland) of the sample was determined to be 8.9.

\section{Simutated gastro-intestinal digestion}

The simulated digestion was done as reported by GilIzquierdo, Zafrilla and Tomás-Barberán [11], with minor modifications. Briefly, to simulate gastric digestion, $1 \mathrm{~g}$ EBN sample was dissolved in $100 \mathrm{~mL}$ distilled water, and kept at $37^{\circ} \mathrm{C}$ for $2 \mathrm{~h}$ in a shaking incubator (50 rpm). The mixture was then boiled $\left(100^{\circ} \mathrm{C}\right)$ for another $30 \mathrm{~min}$ and kept at $55^{\circ} \mathrm{C}$ for $3 \mathrm{~h}$ on the shaking incubator (50 rpm). The $\mathrm{pH}$ of 8.9 was adjusted to 2.0 using HCL, and pepsin (10,000 units) was added. The $\mathrm{pH}$-adjusted sample was subjected to shaking for another $2 \mathrm{~h}$, and boiling for $20 \mathrm{~min}$ (to inactivate pepsin) before bringing it in contact with a dialysis tubing. Snakeskin Pleated Dialysis Tubing (10 K MWCO, Thermo Fisher Scientific Inc., Waltham, USA) containing $2 \mathrm{M} \mathrm{NaHCO}_{3}$ was immersed into the container holding the pepsin-digested EBN samples and subjected to continuous shaking for 10 min until the $\mathrm{pH}$ was 8.0. Pancreatin digestion (36 $\mathrm{mg})$ in the presence of bile extract $(112.5 \mathrm{mg}$ ) was then carried out on the sample with continuous shaking for $2 \mathrm{~h}$ to simulate small intestinal conditions. The sample was boiled after this for $30 \mathrm{~min}$ and cooled, at which point the $\mathrm{pH}$ was 8.9 . The water samples within and outside the dialysis tubing in the container holding the sample was collected and filtered $(0.45 \mu \mathrm{m}$ pore size, Fisher Scientific, Santa Clara, CA, USA). The filtered sample was then used for analyses.

\section{In vitro antixodant testing \\ ABTS and ORAC assays}

Antioxidant potentials of the EBN samples before and after the simulated gastro-intestinal digestion were analysed by investigating their abilities to scavenge the ABTS free radical using the method described previously [12]. Briefly, $\mathrm{K}_{2} \mathrm{~S}_{2} \mathrm{O}_{8}$ solution ( $2.45 \mathrm{uM}$ ) was prepared freshly by dissolving $6.62 \mathrm{mg}$ of $\mathrm{K}_{2} \mathrm{~S}_{2} \mathrm{O}_{8}$ in $10 \mathrm{~mL}$ of distilled water, while $7 \mathrm{mM}$ ABTS was prepared by dissolving $38.4 \mathrm{mg}$ in $10 \mathrm{~mL}$ distilled water. The reagents $\left(\mathrm{K}_{2} \mathrm{~S}_{2} \mathrm{O}_{8}\right.$ and ABTS) were mixed and incubated in the dark at room temperature for $16 \mathrm{~h}$ prior to use. The spectrophotometric absorbance of the mixture at $735 \mathrm{~nm}$ was determined to be $0.700 \pm 0.005$ before use. Then, $20 \mathrm{uL}$ EBN (4-1000 $\mu \mathrm{g} / \mathrm{mL})$ sample or Trolox standard $(1.56-100 \mu \mathrm{g} / \mathrm{mL})$ was mixed with $200 \mathrm{uL}$ of the diluted ABTS solution in a 96 well plate, and the absorbance read at $734 \mathrm{~nm}$. The ABTS radical cation scavenging activity was calculated as the percentage reduction in absorbance, represented by the equation $(y=1.71761 \mathrm{x}+$ $\left.1.3953, \mathrm{R}^{2}=0.9939\right)$.

For ORAC [13], trolox standards $(1.56-100 \mu \mathrm{g} / \mathrm{mL})$ and EBN samples (4-1000 $\mu \mathrm{g} / \mathrm{mL})$ were used. Briefly, $150 \mathrm{uL}$ $8.16 \times 10^{-5} \mathrm{mM}$ fluorescein was added to each well of 96 well plate and $25 \mathrm{uL}$ sample or standard was added. The mixture was then incubated at $37^{\circ} \mathrm{C}$ for 15 mins, and 25 $\mathrm{uL}$ AAPH solvent $(153 \mathrm{uM})$ was added. The fluorescence data was measured using BioTeK Synergy H1 Hybrid Reader (BioTek Instruments Inc., Winooski, VT, USA) with the excitation wave length of $485 \mathrm{~nm}$ and emission 
wave length of $520 \mathrm{~nm}$. The plate was read continuously at intervals of one minute for another $2 \mathrm{~h}$ at $37^{\circ} \mathrm{C}$. ORAC levels were expressed as mole of Trolox equivalents (TE) per mole of antioxidant standard.

\section{Cell culture}

HEPG2 cell line was acquired from ATCC, and cultured using RPMI medium containing glucose, FBS and penicillin/ streptomycin. The cell culture was maintained in a humidified incubator at $37^{\circ} \mathrm{C}$ under $5 \% \mathrm{CO}_{2}$. Upon $80 \%$ confluence in a $75 \mathrm{~cm}^{3}$ flask, cells were seeded into 96 well plate at a concentration of $1^{*} 10^{5}$ and incubated for $24 \mathrm{~h}$ at $37^{\circ} \mathrm{C}$. Then EBN samples (water-extracted and digested, 1.95-1000 ppm) were used to treat the cells for $24 \mathrm{~h}$. MTT was later added to the wells and incubated for another $4 \mathrm{~h}$ at $37^{\circ} \mathrm{C}$ in the dark. Absorbance was read using BioTeK Synergy H1 Hybrid Reader (BioTek Instruments Inc., Winooski, VT, USA) at $540 \mathrm{~nm}$, to detect the amount of MTT formazan product formed.

In another experiment, $300 \mathrm{uM} \mathrm{H}_{2} \mathrm{O}_{2}$ (determined as IC50 from preliminary experiment) was added to HEPG2 cells seeded on a 96 well plate to induce stress, subsequent to treatment with the EBN samples. $\mathrm{H}_{2} \mathrm{O}_{2}$-treated cells were incubated for $1 \mathrm{~h}$, and MTT added for another $4 \mathrm{~h}$ as stated above. Absorbance was read at $540 \mathrm{~nm}$ and cell viability was calculated by using following equation:

Cell viability $(\%)=($ absorbance of samples-absorbance of blank $)$

/(absorbance of control-absorbance of blank) $* 100$

\section{Intracellular antioxidant (DCFH-DA) assay}

DCFH-DA assay was done as reported previously, with minor modifications [14]. Briefly, HEPG2 cells were plated at a density of $1 \times 10^{5}$ /well into 96-well plate and allowed to attach for $24 \mathrm{~h}$. Cells were then washed with PBS and incubated with $10 \mu \mathrm{M}$ DCFH-DA in the medium under $5 \% \mathrm{CO}_{2} / 95 \%$ air at $37^{\circ} \mathrm{C}$ for $30 \mathrm{~min}$. Then, cells were washed again using PBS and incubated with the different treatments (4-1000 ppm EBN) for $24 \mathrm{~h} . \mathrm{H} 2 \mathrm{O} 2(300 \mu \mathrm{M})$ was then added to the cells and the plate was placed on the BioTeK Synergy H1 Hybrid Reader (BioTek Instruments Inc., Winooski, VT, USA) with temperature maintained at $37^{\circ} \mathrm{C}$. The excitation filter was set at $480 \mathrm{~nm}$ and the emission filter was set at $510 \mathrm{~nm}$. The fluorescence from each well was captured continuously and the data points were recorded every $10 \mathrm{~min}$. The data were exported to Excel (Microsoft, Seattle, WA, USA) spreadsheet software and used to plot a line graph showing changes in ROS generation over time.

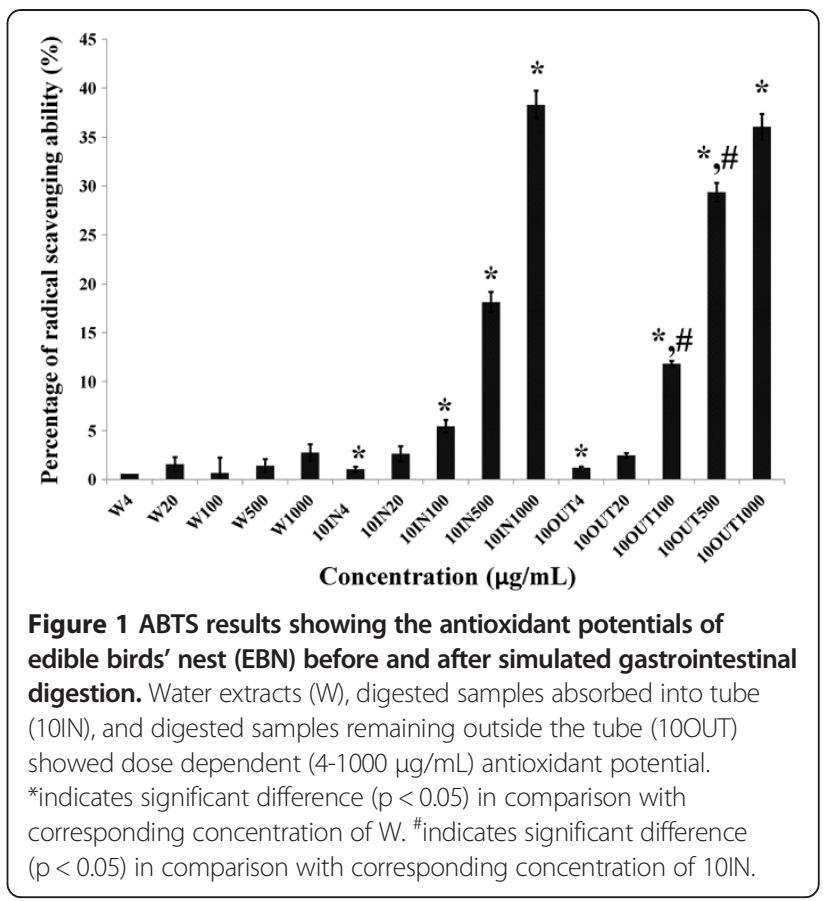

Acridine Orange and Propidium lodide (AO/PI) staining using fluorescence microscope

HepG2 cells were seeded, and later treated with EBN and $300 \mu \mathrm{M} \mathrm{H}_{2} \mathrm{O}_{2}$ as previously described [15]. After the incubation period, the growth media was discarded and the cells stained with the dye mixture $(10 \mu \mathrm{L}$ of $1 \mathrm{mg} / \mathrm{mL}$ AO and $10 \mu \mathrm{L}$ of $1 \mathrm{mg} / \mathrm{mL}$ PI). Stained cells

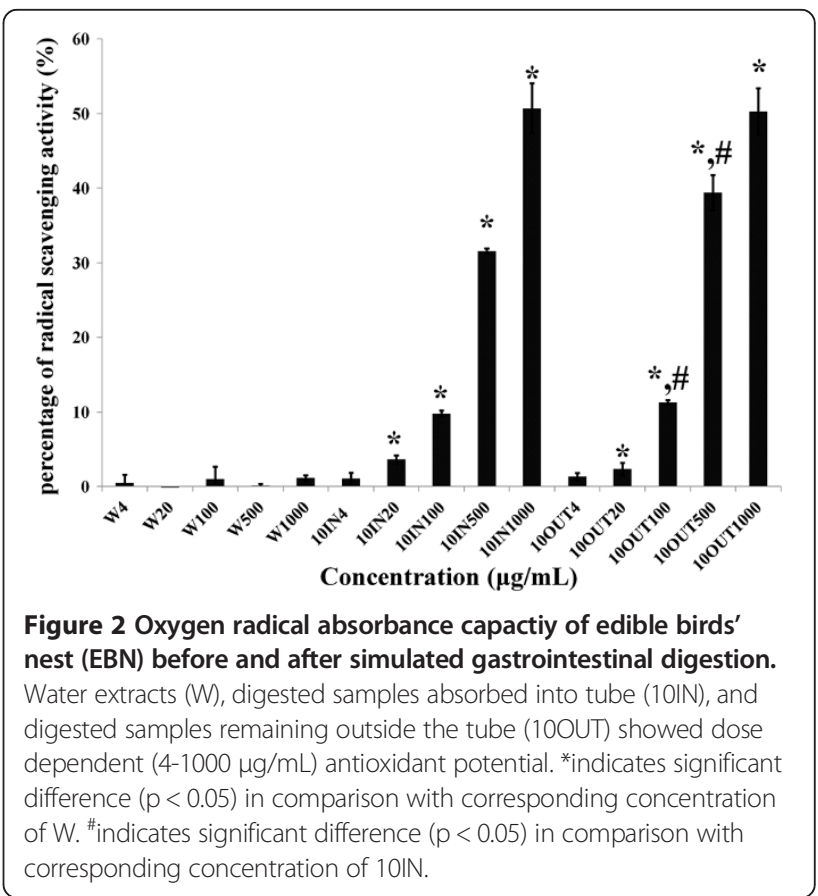



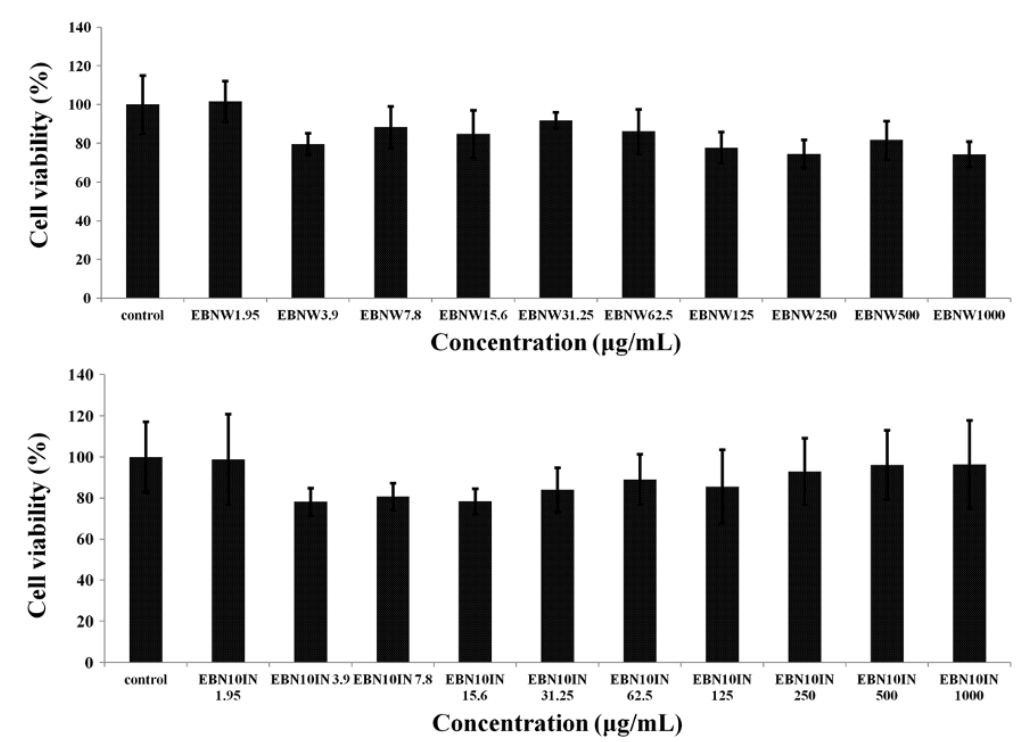

Figure 3 Cytotoxic effects of a) water extract and b) digested samples of edible birds' nest (EBN) on HepG2 cells. EBN water extract (EBNW) and digested samples (EBN1OIN) showed little toxicity to HepG2 cells over concentrations of 1.95 and $1000 \mu \mathrm{g} / \mathrm{mL}$. No significant differences were observed $(p>0.05)$ between the control and different concentrations of EBNW or EBN10IN.

were examined using a confocal microscope (Olympus, Tokyo, Japan). Multiple independent images were taken.

\section{Statistical analysis}

All data are presented as mean $\pm \mathrm{SD}$. The data was evaluated by one-way ANOVA using Statistical Package for Social Sciences software, version 20 (SPSS Inc., Chicago, IL). Differences between the means were assessed using Tukey's multiple comparisons and Student's $t$-test. Statistical significance was considered at $p<0.05$.

\section{Results and discussion}

\section{Antioxidant potentials of EBN samples}

Figure 1 shows the ABTS scavenging potentials of EBN samples. Water extract of EBN samples, over the range of 4 to $1000 \mu \mathrm{g} / \mathrm{mL}$, prior to digestion had the lowest scavenging potential (with a maximum of $1 \%$ ) compared to the samples subjected to simulated gastrointestinal digestion. In comparison, simulated gastrointestinal digestion increased the scavenging potential $(\mathrm{p}<0.05)$ due to EBN with slightly higher values for samples remaining outside the dialysis tubing ( $38 \%$ at $1000 \mu \mathrm{g} / \mathrm{mL}$ ) compared with samples inside the tubing ( $36 \%$ at $1000 \mu \mathrm{g} /$ $\mathrm{mL}$ ). The dialysis tubing represents a model of absorption in the gastrointestinal system, and the results suggested that following consumption of EBN, it is likely that the unabsorbed antioxidants would be higher than those absorbed. This is in line with what has been reported previously [16]; lactoferrin is thought to be absorbed minimally with most of it remaining in the gut where it modulates gut health, and the same may be true for other bioactives. The findings from this experiment also suggest that digestion of EBN leads to release of it bioactive compounds, in line with what is expected of food bioactives under gastrointestinal digestion [9].

Furthermore, ORAC results on Figure 2 show similar patterns of scavenging activities to the ABTS results. Water extract of EBN showed little scavenging activity (1\%) even at the highest concentration used, compared with the samples subjected to simulated gastrointestinal digestion, which showed a dose-dependent activity that was maximal $(50 \%)$ for samples in and outside the tubing at the highest concentration $(1000 \mu \mathrm{g} / \mathrm{mL})$. The similar scavenging activities observed for samples within

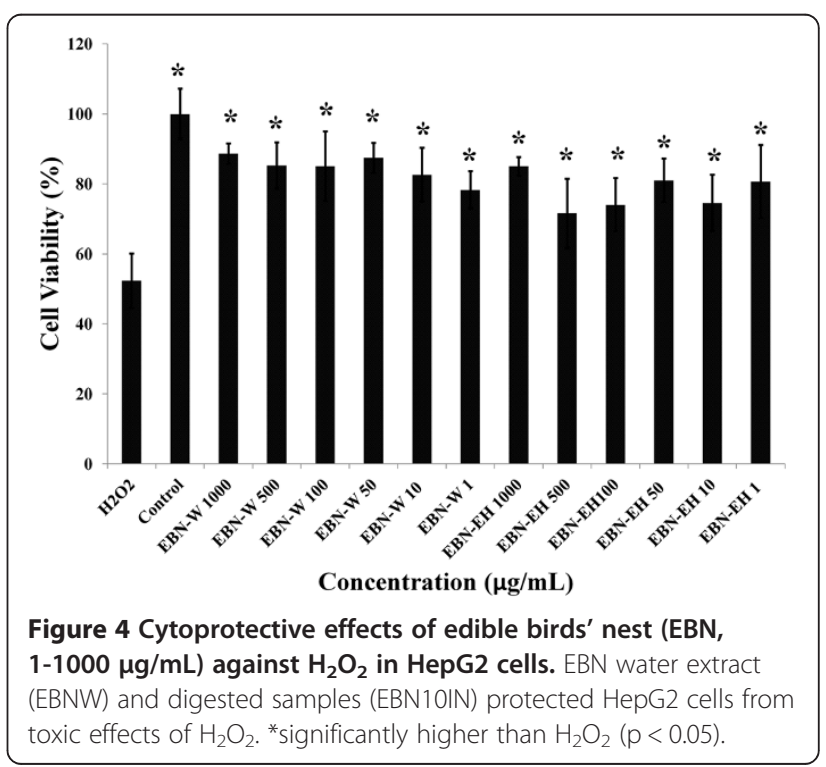




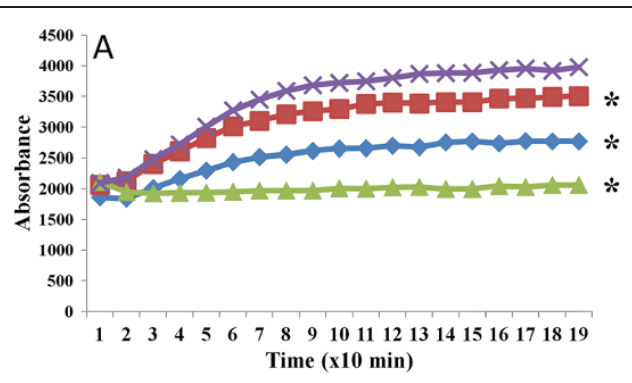

$$
\begin{aligned}
& - \text { EBN10IN } \\
& =\text { EBNW } \\
& + \text { control } \\
& * \mathrm{H} 2 \mathrm{O} 2
\end{aligned}
$$
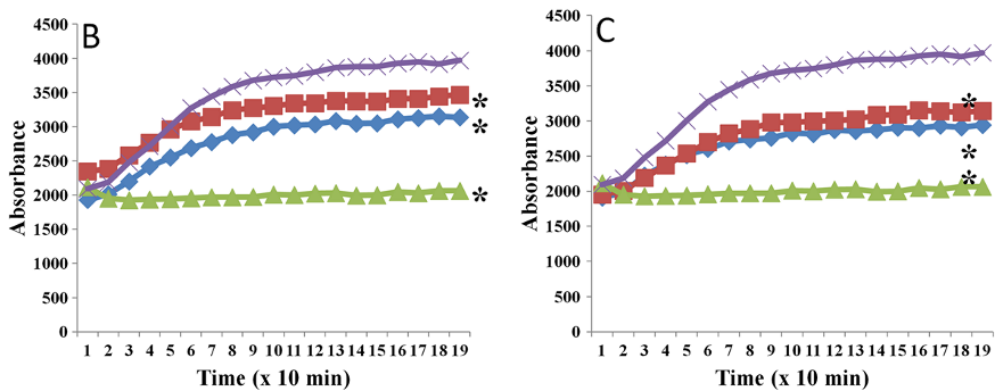

Figure 5 Effect of edible birds' nest (EBN) (A) 4, (B) 20 and (C) $500 \mu \mathrm{g} / \mathrm{mL}$ on intracellular ROS determination using DCFH-DA. Water extracts (EBNW) and digested samples (EBNW1OIN), reduced levels of ROS generation compared with the $\mathrm{H}_{2} \mathrm{O}_{2}$-treated group. * ${ }^{*}$ ignificantly lower than $\mathrm{H}_{2} \mathrm{O}_{2}(\mathrm{p}<0.05)$.

and outside the dialysis tubing, suggested that as much antioxidants absorbed are left in the gut likely through passive-mediated transport of the molecules responsible for the antioxidant activity. These results suggest that when EBN is digested in the gut, much of its antioxidants are absorbed through the gut while others remain within the lumen to exact local effects [16]. Also, the ORAC results indicate that these findings may have clinical significance since ORAC has been reported to reproduce what happens in biological systems.

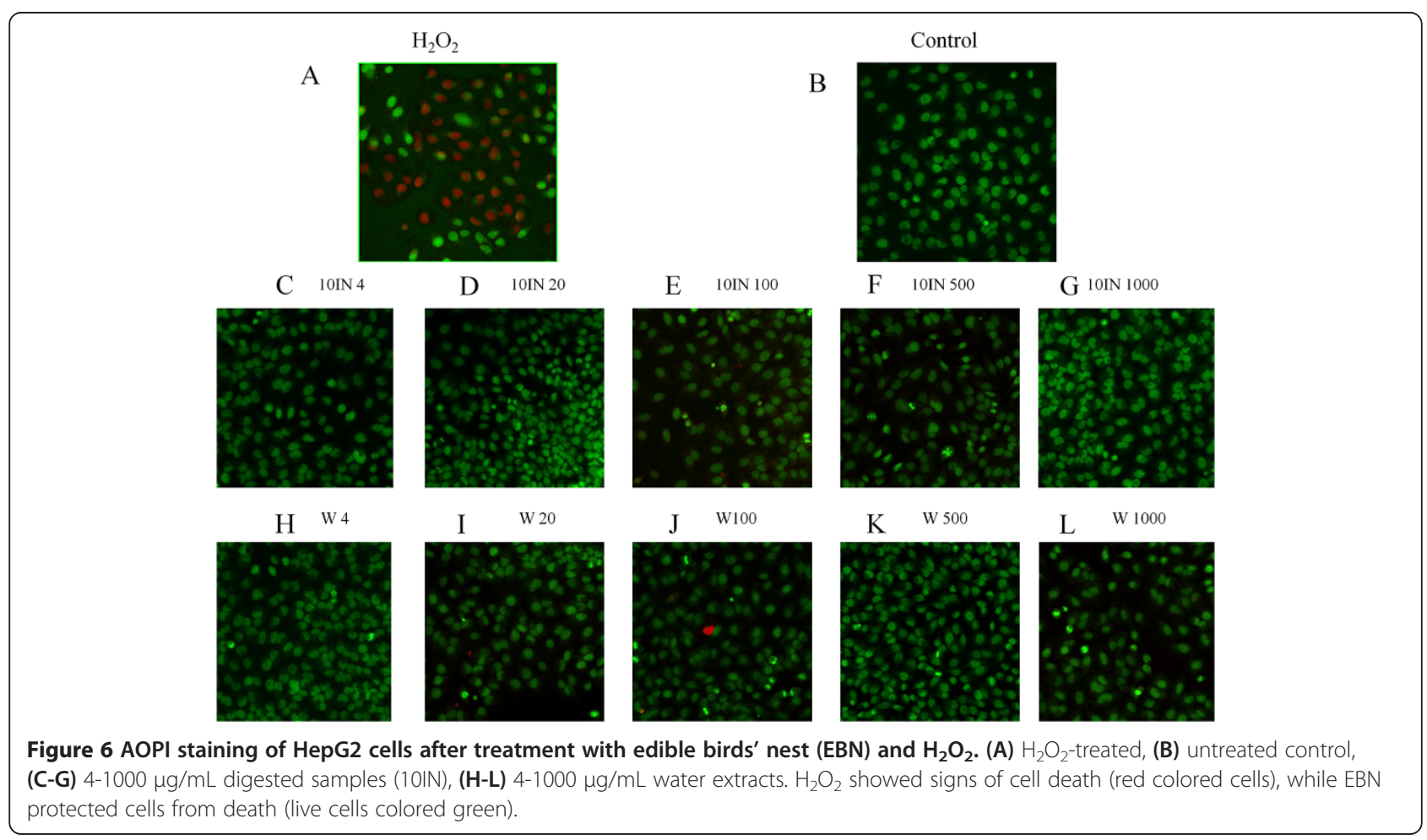




\section{Cell toxicity and viability assays}

To determine the effects of the EBN water extracts with and without digestion, the MTT assay was used. After treatment for $24 \mathrm{~h}$, there were no significant signs of toxicity due any of the EBN extracts. Figure 3 shows the cytotoxicity results for water extracts of EBN before and after digestion (sample within dialysis tubing), respectively. The non-digested samples showed a cell viability of more than $80 \%$ over the entire range of treatments. The digested samples also showed similar results but interestingly had higher cell viabilities with higher concentrations of the extract. Additionally, as can be recalled, $300 \mathrm{uM} \mathrm{H}_{2} \mathrm{O}_{2}$ produced $50 \%$ cell viability on HEPG2 cells but in the presence of the EBN extracts (digested and undigested), cell viability was over $80 \%$ across all tested doses (Figure 4).

\section{Intracellular antioxidant assay (DCFH-DA) assay}

The DCFH-DA assay is used to measure intracellular antioxidant activity and although it has limitations, it has been shown to provide valuable insights into possible antioxidant activity [14]. In the present study, the addition of $\mathrm{H}_{2} \mathrm{O}_{2}$ showed high absorbance readings (fluorescence unit of 3975 after 190 mins, Figure 5A) indicating that high numbers of the cells had died. On the other hand, in the presence of the EBN extracts (4, 20 and $500 \mu \mathrm{g} / \mathrm{mL}$, Figures $5 \mathrm{~A}, \mathrm{~B}$ and $\mathrm{C}$, respectively), there was a reduction of this intensity especially with the digested samples (2700, 3100 and 2900 fluorescence units, respectively), which tended towards normal (fluorescence unit of 2000). These results also suggest that in the presence of the EBN extracts, HEPG2 cells are conferred some protection against $\mathrm{H}_{2} \mathrm{O}_{2}$.

\section{AOPI staining}

When cells are stained with AOPI, the dead cells produce a classical orange to red flourescence while live cells will show a green glow [15]. In this study, $\mathrm{H}_{2} \mathrm{O}_{2}$ showed a pattern indicative of dead cells with AOPI staining (Figure 6A) in contrast to untreated controls that showed no signs of dead cells (Figure 6B). Treatment with extracts in the presence of $\mathrm{H}_{2} \mathrm{O}_{2}$ protected the cells from death as shown on Figures 6C-6L.

In aggregate, the findings in this study are in agreement that EBN water extract produces antioxidant activity which is more pronounced when the samples are digested, as suggested by the results of the simulated gastrointestinal digestion in this study. The findings also suggest that almost an equal amount of antioxidants are likely absorbed by the gut as those unabsorbed following digestion of EBN. These indicate that the antioxidants bound to their matrix in EBN are released upon digestion and will hence be available for bioactivity, as shown by the results of enhanced antioxidant activity in the
ORAC assay for the digested samples that collected in and out of the dialysis tubing in comparison to the undigested water extract. The results of the cell toxicity and viability assays support this hypothesis, which was further corroborated by the AOPI staining results.

\section{Conclusions}

In this study, EBN samples subjected to simulated gut digestion showed enhanced antioxidant activity even in the presence of $\mathrm{H}_{2} \mathrm{O}_{2}$ as evidenced by the results of antioxidant, and cell viability and cytotoxicity assays. The findings were further supported by the results of AOPI staining. The overall results suggest that when EBN is subjected to gut digestion, its antioxidants are released from their bound matrix and may exert significant antioxidant activity. The findings show that EBN has enhanced antioxidant activity after digestion, which may possibly underlie some of its functional effects after consumption, and is worth studying further.

\section{Abbreviations}

AAPH: 2,2'-azobis (2-amidinopropane) dihydrochloride; ABTS: 2,2'-azino-bis [3-ethylbenzothiazoline-6-sulphonic acid; AO-PI: Acridine orange-propidium iodide; DCFH-DA: Dichloro-dihydro-fluorescein diacetate; EBN: Edible birds' nest; $\mathrm{H}_{2} \mathrm{O}_{2}$ : hydrogen peroxide; $\mathrm{K}_{2} \mathrm{~S}_{2} \mathrm{O}_{8}$ : Potassium persulphate; MTT: (3-[4,5dimethylthiazol-2-yl]-2,5-diphenyl-tetrazolium bromide); $\mathrm{NaHCO}_{3}$ : Sodium biocarbonate; ROS: Reactive oxygen species.

\section{Competing interests}

The authors declare that they have no competing interest.

\section{Authors' contributions}

$\mathrm{ZY}$ and $\mathrm{MI}$ conceived the idea for this study, while ZY conducted the experiments, and together with MUI drafted the manuscript. MUI and MI reviewed the manuscript and approved the final version for submission. All authors read and approved the final manuscript.

\section{Acknowledgements}

We thank Universiti Putra Malaysia (UPM) for sponsoring this research (vote no 5450666). The authors also thank the staff of the Laboratory of Molecular Biomedicine for their assistance with this study.

\section{Author details}

${ }^{1}$ Laboratory of Molecular Biomedicine, Institute of Bioscience, Universiti Putra Malaysia, 43400 Serdang, Selangor, Malaysia. ${ }^{2}$ Cardiology Department, Affiliated Hospital of Chengde Medical University, 067000 Chengde, Hebei, China. ${ }^{3}$ Department of Nutrition and Dietetics, Faculty of Medicine and Health Sciences, Universiti Putra Malaysia, 43400 Serdang, Selangor, Malaysia.

Received: 19 June 2014 Accepted: 14 November 2014

Published: 5 December 2014

\section{References}

1. Hamzah Z, Ibrahim NH, Jaafar MN, Lee BB, Hashim O, Hussin K: Nutritional properties of edible bird nest. J Asian Sci Res 2013, 3(6):600-607.

2. Wong RS: Edible bird's nest: food or medicine? Chin J Integr Med 2013, 19(9):643-649.

3. Chua KH, Lee TH, Nagandran K, Yahaya NHM, Lee CT, Tjih ETT, Aziz RA Edible Bird's nest extract as a chondro-protective agent for human chondrocytes isolated from osteoarthritic knee: in vitro study. BMC Complement Alternat Med 2013, 13(1):19.

4. Vimala B, Hussain H, Nazaimoon WW: Effects of edible bird's nest on tumour necrosis factor-alpha secretion, nitric oxide production and cell viability of lipopolysaccharide-stimulated RAW 264.7 macrophages. Food Agric Immunol 2012, 23(4):303-314. 
5. Chua YG, Bloodworth BC, Leong LP, Li SFY: Metabolite profiling of edible bird's nest using gas chromatography/mass spectrometry and liquid chromatography/mass spectrometry. Rapid Commun Mass Spectrom 2014, 28(12):1387-1400

6. Liu X, Lai X, Zhang S, Huang X, Lan Q, Li Y, Li B, Chen W, Zhang Q, Hong D, Yang G: Proteomic profile of edible bird's nest proteins. J Agric Food Chem 2012, 60(51):12477-12481.

7. Marcone MF: Characterization of the edible bird's nest the "Caviar of the East". Food Res Int 2005, 38(10):1125-1134.

8. Aruoma Ol: Free radicals, oxidative stress, and antioxidants in human health and disease. J Am Oil Chem Soc 1998, 75(2):199-212.

9. Holst B, Williamson G: Nutrients and phytochemicals: from bioavailability to bioefficacy beyond antioxidants. Curr Opin Biotechnol 2008, 19(2):73-82.

10. Chan KW, Khong NM, lqbal S, Umar IM, Ismail M: Antioxidant property enhancement of sweet potato flour under simulated gastrointestinal pH. Int J Mol Sci 2012, 13(7):8987-8997.

11. Gil--zquierdo A, Zafrilla P, Tomás-Barberán FA: An in vitro method to simulate phenolic compound release from the food matrix in the gastrointestinal tract. Eur Food Res Technol 2002, 214(2):155-159.

12. Kim H, Moon JY, Kim H, Lee DS, Cho M, Choi HK, Kim YS, Mosaddik A, Cho SK: Antioxidant and antiproliferative activities of mango (Mangifera indica L.) flesh and peel. Food Chem 2010, 121(2):429-436.

13. Handelman GJ, Cao G, Walter MF, Nightingale ZD, Paul GL, Prior RL, Blumberg JB: Antioxidant capacity of oat (Avena sativa L.) extracts. 1. Inhibition of low-density lipoprotein oxidation and oxygen radical absorbance capacity. J Agr Food Chem 1999, 47(12):4888-4893.

14. Wang H, Joseph JA: Quantifying cellular oxidative stress by dichlorofluorescein assay using microplate reader. Free Radic Biol Med 1999, 27(5):612-616.

15. Azmi NH, Ismail N, Imam MU, Ismail M: Ethyl acetate extract of germinated brown rice attenuates hydrogen peroxide-induced oxidative stress in human SH-SY5Y neuroblastoma cells: role of anti-apoptotic, pro-survival and antioxidant genes. BMC Complement Alternat Med 2013, 13(1):177.

16. Kuwata H, Yamauchi K, Teraguchi S, Ushida Y, Shimokawa Y, Toida T, Hayasawa $\mathrm{H}$ : Functional fragments of ingested lactoferrin are resistant to proteolytic degradation in the gastrointestinal tract of adult rats. J Nutr 2001, 131(8):2121-2127.

doi:10.1186/1472-6882-14-468

Cite this article as: Yida et al.: In vitro bioaccessibility and antioxidant properties of edible bird's nest following simulated human gastro-intestinal digestion. BMC Complementary and Alternative Medicine 2014 14:468.

\section{Submit your next manuscript to BioMed Central and take full advantage of:}

- Convenient online submission

- Thorough peer review

- No space constraints or color figure charges

- Immediate publication on acceptance

- Inclusion in PubMed, CAS, Scopus and Google Scholar

- Research which is freely available for redistribution 